\title{
IT'S NOT JUST ABOUT THE KNIFE: RELIGIOUS AND SECULAR KILLING FOR MEAT
}

\author{
BRIAN STEIN
}

CONTENTS

I

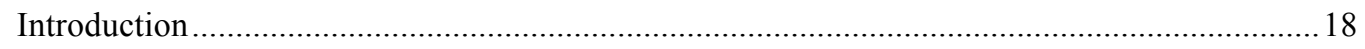

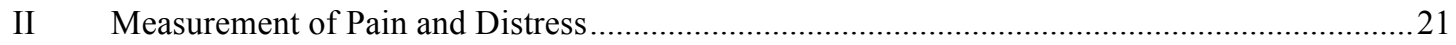

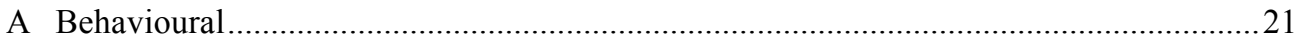

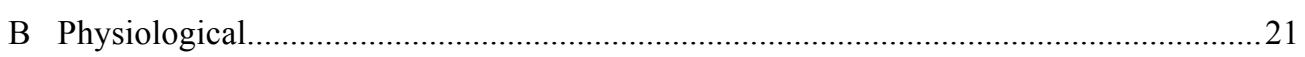

C Brain Physiology .................................................................................................... 21

D Evidence of Adverse Events ..................................................................................22

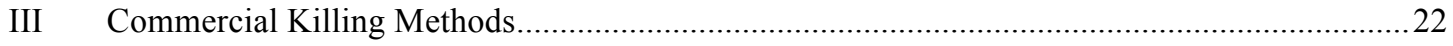

A The Process of Industrial Killing .......................................................................... 22

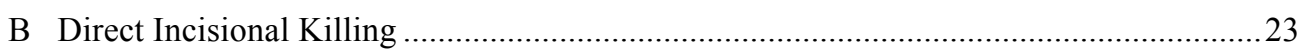

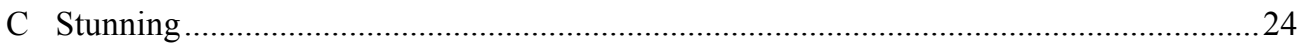

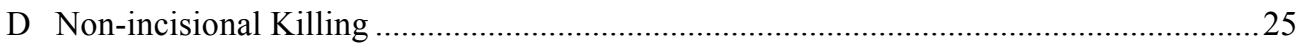

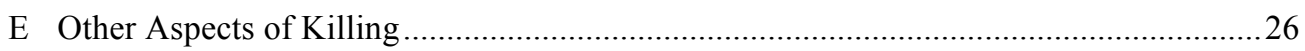

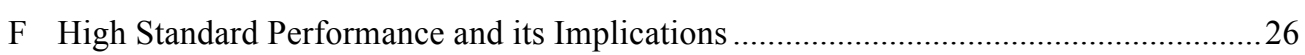

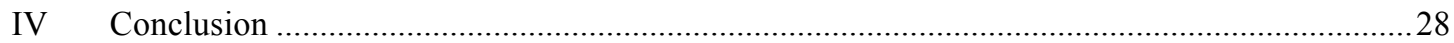

\section{INTRODUCTION}

Humans have a tremendous appetite for meat. In 2011 about 2.6 billion of the large animals considered in the primary article by Seamus Brand ${ }^{1}$ were killed

MB BS (Hons) (University of Adelaide); FRACP; Senior Lecturer, Department of Medicine University of Adelaide; Senior Consultant, Department of Medical Oncology, Royal Adelaide Hospital.

1 Seamus Brand, 'Australian Live Animal Export: A Comparative Examination of Viable Alternatives' (this volume). 
for meat. ${ }^{2}$ In Australia, approximately 3800000 large animals ${ }^{3}$ and 600000 000 chickens were killed for meat in $2014^{4}$ in all manners (halal, kosher and commercial). Meat production is rising steadily ${ }^{5}$ and in lower income countries it functions economically as a luxury good. ${ }^{6}$

The ethical issues arising from eating meat have been documented for over 2 500 years. $^{7}$ More contemporary appreciation would add that not only do humans not need meat, but also that those who eat significant quantities benefit from eating less. ${ }^{8}$ Furthermore the committed partner in the eating relationship is now demonstrated to be far more subtle than previously thought. The creatures providing the meat can no longer be considered 'dumb animals'; the concept of so called 'lower animals' as senseless automatons purely driven by instinct is no longer tenable. To wit: cognition is now experimentally demonstrated in many species of vertebrates, including birds. ${ }^{9}$ Consciousness is likewise strongly argued to be present in vertebrates including reptiles, birds, and mammals, ${ }^{10}$ and sentience is a subject worthy of

2 Food and Agricultural Organization of the United Nations, FAOSTAT Statistical Database $<$ faostat3.fao.org $>$.

3 Australian Bureau of Statistics, 7218.0.55.001-Livestock and Meat, Australia 2015 $<$ abs.gov.au $>$.

$4 \quad$ Australian Chicken Meat Federation Chicken Production < chicken.org.au>.

5 World Health Organization, Global and Regional Food Consumption Patterns and Trends $<$ http://www.who.int/nutrition/topics/3 \_foodconsumption/en/index4.html >.

6 David L Ortega, H Holly Wang and James S Eales, 'Meat Demand in China' (2009) 1 China Agricultural Economic Review 410; Abdellah Mdafri and B Wade Brorsen, 'Demand for Red Meat, Poultry, and Fish in Morocco: An Almost Ideal Demand System' (1993) 9 Agricultural Economics 155.

7 Colin Spencer, The Heretic's Feast: A History of Vegetarianism (University Press of New England, 1995).

8 Kate Marsh, Carol Zeuschner and Angela Saunders, 'Health Implications of a Vegetarian Diet: A Review’ (2012) 6 American Journal of Lifestyle Medicine 250; Pramil N Singh, Joan Sabaté and Gary E Fraser, 'Does Low Meat Consumption Increase Life Expectancy in Humans?' (2003) 78 American Journal of Clinical Nutrition 5265; Barry M Popkin, 'Reducing Meat Consumption Has Multiple Benefits for the World's Health' (2009) 169 Archives of Internal Medicine 543; Rashmi Sinha et al, 'Meat Intake and Mortality: A Prospective Study of over Half a Million People' (2009) 169 Archives of Internal Medicine 562.

9 D R Griffin and G Speck, 'New Evidence of Animal Consciousness' (2004) 7 Animal Cognition 5.

10 Gary E Varner, Personhood, Ethics, and Animal Cognition: Situating Animals in Hare's Two-Level Utilitarianism (Oxford University Press, 2012); Colin Allen and Michael Trestman, 'Animal Consciousness' in Edward N Zalta (ed), The Stanford Encyclopedia of Philosophy (Summer 2015 Edition) <http://plato.stanford.edu/entries/consciousnessanimal/>. 
systematic review. ${ }^{11}$ Nociception (ie, the neural process of encoding noxious stimuli) is widespread in animals; however, the question of pain and suffering is more difficult to answer. But with serious consideration given to the possibility that so-called 'simple animals' like invertebrates can experience pain, ${ }^{12}$ the debate has moved past argument that those with more complex neural structure do not feel pain.

The live transport of animals as part of kosher (Jewish) and halal (Muslim) meat production is a matter of recent controversy, as described in the primary article. Attention is paid to the particulars of kosher and halal slaughter because of the general presumption that these methods are cruel, and this perception has led some countries such as Denmark to ban these methods of slaughter. ${ }^{13}$ In contrast, some members of the Muslim community have claimed that data demonstrates halal slaughter to be the most humane method; ${ }^{14}$ whereas others are more critical of the entire industrial process. ${ }^{15}$

It is clear that it is easy to cause great suffering in the killing of animals through terrible practice. While this may be satisfactory for the evening news, it does not cause the sceptical to examine the issue, and more importantly, it does not address the key questions. In best commercial practice these questions are:

1. Is incisional slaughter painful?

2. Can stunning alleviate pain and suffering?

3. Is the best non-incisional method free of pain?

For the purposes of this comment I have restricted enquiry to large animals in keeping with the theme proposed by the primary article. Part II begins by

11 Helen S Proctor, Gemma Carder and Amelia R Cornish, 'Searching for Animal Sentience: A Systematic Review of the Scientific Literature’ [2013] Animals 882.

12 Robert W Elwood, 'Pain and Suffering in Invertebrates' (2011) 52 ILAR Journal 175; European Food Safety Authority-AHAW Panel, 'Opinion on the "Aspects of the Biology and Welfare of Animals Used for Experimental and Other Scientific Purposes"” (2005) 292 The European Food Safety Authority Journal, 1

$<$ http://www.efsa.europa.eu/sites/default/files/scientific_output/files/main_documents/ahaw _op_ej292_labanimalswelfare_en1\%2C7.pdf>.

13 Adam Withnall, 'Denmark Bans Kosher and Halal Slaughter as Minister Says "Animal Rights Come Before Religion”' The Independent (online), 18 February 2014,

$<$ http://www.independent.co.uk/news/world/europe/denmark-bans-halal-and-kosherslaughter-as-minister-says-animal-rights-come-before-religion-9135580.html>.

14 Karima Hamdan, Halal Hysteria - the Case Against Stunning (undated) $<$ http://halalmedia.net/halal-hysteria-the-case-against-stunning/>.

15 S Abdul Rahman et al, 'Islam and Animal Welfare with Special Reference to Cruelty to Animals During Transport and Slaughter' (2012) 28 Journal of Commonwealth Veterinary Association 27. 
surveying the different measures of pain and distress in animals; and Part III presents an overview of the commercial methods used to kill animals. In Part IV, I argue that while the available evidence confirms that direct incisional killing causes pain and may lead to significant suffering in some animals, the deeper issue that must be confronted arises from the fact that even when best commercial practices are followed, enormous numbers of animals experience pain or distress in the final period of their life regardless of whether they are killed by halal, kosher or secular methods of slaughter.

\section{MEASUREMENT OF PAIN AND Distress}

\section{A Behavioural}

Animals exhibit a series of aversive behaviours in the face of stressful situations that the most cursory knowledge renders familiar. Temple Grandin has shown that animal vocalization is strongly associated with distressing events like electrical prodding. ${ }^{16}$

\section{B Physiological}

Mammals and other vertebrates respond to stressful events with activation of the autonomic nervous system, and production of 'stress hormones' typically from the adrenal. Body temperature may also rise. With extreme fatigue there may be a switch to anaerobic metabolism resulting in increased lactate levels. Cortisol and adrenalin levels can be measured in blood, as can lactate. ${ }^{17}$

\section{Brain Physiology}

It is possible to record the electrical activity of the brain (EEG). Gibson et $a 1^{18}$ have documented particular EEG patterns that correlate with painful

16 Temple Grandin, 'Cattle Vocalizations Are Associated with Handling and Equipment Problems at Beef Slaughter Plants’ (2001) 71 Applied Animal Behaviour Science 191.

17 L N Edwards et al, 'Use of Exsanguination Blood Lactate to Assess the Quality of PreSlaughter Pig Handling' (2010) 86 Meat Science 384; Temple Grandin, 'Assessment of Stress During Handling and Transport' (1997) 75 Animal Science 249.

18 T J Gibson et al, 'Electroencephalographic Responses of Halothane-Anaesthetised Calves to Slaughter by Ventral-Neck Incision Without Prior Stunning.' (2009) 57 New Zealand Veterinary Journal 77; C B Johnson et al, 'Pain Perception at Slaughter' (2012) 21 Animal Welfare 113. 
stimuli. These methods have been corroborated by others and are a powerful tool. ${ }^{19}$

\section{Evidence of Adverse Events}

Certain events are de facto unpleasant. A clear example is hoisting the animal onto the bleed rail while it is still able to feel pain.

\section{COMMERCIAL KILLING METHODS}

\section{A The Process of Industrial Killing}

The Qur'anic ideal ${ }^{20}$ of the animal fed, watered and quietly taken to its place of slaughter where its life is swiftly ended by skilful use of the knife is very far removed from the reality of commercial meat production. Animals are typically transported some distance, marshalled and evaluated, and if fit for slaughter moved into a holding pen and then into a passage ending in the actual restraint and killing area. (See, for example Temple Grandin ${ }^{21}$ for more detailed descriptions, and $\mathrm{M} \mathrm{H}$ Anil ${ }^{22}$ for an overview of stunning, and the requirements of halal and kosher slaughter).

Temple Grandin, one of the doyens of the field, regards the following audit outcomes as indicative of good or excellent standards: ${ }^{23}$

- Captive bolt or gunshot; $95 \%$ rendered insensible with one shot, $99 \%$ is an excellent score, or

- $\quad$ Electric stunning; 99\% correct electrode placement.

19 Zulkifli I et al, 'Changes in Blood Parameters and Electroencephalogram of Cattle as Affected by Different Stunning and Slaughter Methods in Cattle' (2014) 54 Animal Production Science 187.

20 S Abdul Rahman and Aidaros, H, 'Islam and Animal Welfare with Special Reference to Cruelty to Animals During Transport and Slaughter.' (2012) 28 Journal of Commonwealth Veterinary Association 27.

${ }^{21}$ Temple Grandin, 'Making Slaughterhouses More Humane for Cattle, Pigs, and Sheep.' [2013] Annual Review of Animal Biosciences 491; Cécile Bourguet et al, 'Behavioural and Physiological Reactions of Cattle in a Commercial Abattoir: Relationships with Organisational Aspects of the Abattoir and Animal Characteristics' (2011) 88 Meat Science 158; Temple Grandin, 'Euthanasia and Slaughter of Livestock' (1994) 204 Journal of the American Veterinary Medical Association 1354.

22 M Haluk ANIL, 'Effects of Slaughter Method on Carcass and Meat Characteristics in the Meat of Cattle and Sheep' (EBLEX, 2012) <http://beefandlamb.ahdb.org.uk/wp/wpcontent/uploads/2013/04/slaughter_and_meat_quality_feb_2012-final-report.pdf $>$.

23 Grandin, 'Making Slaughterhouses More Humane', above n 21, 505. 
- Insensibility; $100 \%$ rendered insensible to pain before hoisting or hanging on the bleed rail.

- Vocalization; $5 \%$ or less of the cattle or pigs vocalizing in the stun box or restrainer.

- Falling; $1 \%$ or less of the animals falling during handling in any part of the facility.

- Electric prods: $75 \%$ or more of the animals moved with no electric prod; $95 \%$ is excellent.

\section{B Direct Incisional Killing}

For kosher and halal butchery, the animal is restrained and a long sharp knife is drawn across the throat to sever the major vessels, which must be done in a single pass. The incision must be deep: adequate depth is ensured by stipulating incision of the trachea and oesophagus, which also involves cutting the cervical nerve plexus. The animal should be conscious, should not witness the slaughter of others, and should not see the knife. In best practice the length of the knife is important, as is the method of restraint: inferior methods take much longer for the animal to receive the killing stroke, and are associated with more struggling. ${ }^{24}$ While the incision does sever a significant component of the blood supply to the brain, the prohibition of beheading the animal implies that the vertebral arteries (especially in cattle) are not severed, and there will be blood supply to the brain until the loss of blood volume causes complete circulatory collapse. ${ }^{25}$

Killing by standard halal or kosher means does give an EEG pain signature. ${ }^{26}$ Once the animal collapses from loss of blood then insensibility rapidly ensues. However, this takes time. It is at least 2-8 seconds in sheep but it may be up to 20 seconds. ${ }^{27}$ Larger animals with greater blood volume take longer: N G Gregory et al report an average of 20 seconds for collapse, and about

24 A Velarde et al, 'Religious Slaughter: Evaluation of Current Practices in Selected Countries' (2014) 96 Meat Science 278.

25 K Nakyinsige et al, 'Stunning and Animal Welfare from Islamic and Scientific Perspectives' (2013) 95 Meat Science 352.

26 Zulkifli et al, 'Changes in Blood Parameters', above n 19; Gibson et al, 'Electroencephalographic Responses', above n 18.

27 Paul H Hemsworth et al, 'A Scientific Comment on the Welfare of Sheep Slaughtered Without Stunning' (Biosecurity Victoria, Department of Primary Industries, 2009) $<$ http://www.australiananimalwelfare.com.au/app/webroot/files/upload/files/welfare-sheepslaughter.pdf $>$. 
$15 \%$ of animals stood again before final expiry. ${ }^{28}$ While some report no behavioural reaction to incisional slaughter, ${ }^{29}$ this does not appear to offer sufficient reassurance given these data. Presence of blood in the respiratory tract may also be distressing, depending on the duration and degree of consciousness. This occurred in a majority of non-stunned halal killed cattle, less in kosher killed cattle and the least in stunned cattle who generally are not breathing. ${ }^{30}$

In secular killing the general consensus is that incisional slaughter causes pain, ${ }^{31}$ and consequently this method is not allowed without stunning. Some countries have outlawed direct incisional killing in any circumstance.

\section{Stunning}

In secular killing direct incisional killing must be preceded by stunning to render the animal unconscious for the killing stroke. Stunning is permitted by some halal authorities, but is not permitted for kosher slaughter. Stunning can be accomplished by inhalation of carbon dioxide, electrical shock, or mechanical trauma. In electrical stunning, a high amperage current is applied to the head, resulting in loss of consciousness associated with an epileptic seizure. Consciousness appears to be lost and subsequent procedures, if applied prior to return of consciousness, are thought to be painless. If animals are dehydrated, the effectiveness is lowered, and the appliance must be correctly applied. ${ }^{32}$

Captive bolt mechanical stunning delivers a direct blow to the head via a bolt fired from a device. The bolt remains captive in the device and results in cerebral cortical trauma without penetration of the skull. Captive bolt

28 N G Gregory et al, 'Time to Collapse Following Slaughter Without Stunning in Cattle' (2010) 85 Meat Science 66.

29 Grandin, 'Euthanasia and Slaughter of Livestock', above n 21.

30 K Von Holleben et al, 'Blood in the Respiratory Tract During Slaughter with and Without Stunning in Cattle’ (2009) 82 Meat Science 13.

31 EFSA, 'Welfare Aspects of Animal Stunning and Killing Methods' (Scientific Report of the Animal Health and Welfare Panel (AHAW/04-027), European Food Safety Authority, 2004) $1<$ http://freepdfs.net/european-food-safety-authority-ahaw04-027-edepot/60334490a41e0a3ba03986fcf29aa64b/>; FAWC, 'Report of the Welfare of Farmed Animals at Slaughter or Killing. Part 1: Red Meat Animals' (Farm Animal Welfare Council, 2003) 1 :

$<$ https://www.gov.uk/government/uploads/system/uploads/attachment_data/file/325241/FA WC_report_on_the_welfare_of_farmed_animals_at_slaughter_or_killing_part_one_red_me at_animals.pdf $>$.

32 Nakyinsige et al, above n 25. 
stunning appears less effective than penetrative bolt, ${ }^{33}$ with greater stress response and greater EEG disturbance. Consciousness in cattle begins to return after 20 seconds and basic reflexes are present after 35 seconds. ${ }^{34}$ The device can misfire, may be ineffective with thick skulled or very hairy animals, and may cause penetrating trauma with thin skulled animals. In the European Union, concerns about the effectiveness of non-penetrating captive bolts have resulted in a limit on their use to animals under $10 \mathrm{~kg} .{ }^{35}$

There are also several other methods in use or research. Inhalation of carbon dioxide causes gradual loss of consciousness, but may cause significant aversive reactions. ${ }^{36}$ It is not generally suitable for cattle and sheep, and is mostly used for slaughter of pigs. ${ }^{37}$ Microwave heating and magnetic stimulation of the brain have both been used for stunning in non-commercial settings, and the latter might be acceptable for halal or kosher killing if it became commercially feasible. ${ }^{38}$

\section{Non-incisional Killing}

The commonest commercial method is captive penetrating bolt. A device fires a retractable rod which penetrates the skull and causes direct brain trauma and a shock wave effect that destroys brain tissue. It requires skill and is subject to misfire. ${ }^{39}$ EEG studies confirm that, if correctly used, penetrative bolts lead to instant loss of consciousness ${ }^{40}$ with no EEG pain response. ${ }^{41}$

33 CSIRO Meat Industry Services, Meat Technology Update. Effect of Slaughter Method on Animal Welfare and Meat Quality (2011)

$<\mathrm{http} / / /$ www.ampc.com.au/site/assets/media/Factsheets/Livestock-Animal-Health-WelfareTransport-Biosecurity/MTU_2011_Effect-of-slaughter-method-on-animal-welfare-andmeat-quality.pdf $>$.

34 Nakyinsige et al, above $\mathrm{n} 25$.

35 Anil, M H, 'Effects of Slaughter Method on Carcass and Meat Characteristics in the Meat of Cattle and Sheep' (EBLEX, 2012) <http://beefandlamb.ahdb.org.uk/wp/wpcontent/uploads/2013/04/slaughter_and_meat_quality_feb_2012-final-report.pdf $>$.

36 Jean-Loup Rault and Ellen Jongman, 'Scientific Commentary: Carbon Dioxide (CO2) for the Stunning of Pigs' (Animal Welfare Science Centre, 2014) $<$ http://www.animalwelfare.net.au/sites/default/files/Scientific\%20commentaryCO2\%20as\%20stunning\%20for\%20pigs-4.pdf $>$; Temple Grandin and Gary C Smith, 'Animal Welfare and Humane Slaughter', Agricultural Mechanization And Automation Vol II (2004) <http://www.eolss.net/sample-chapters/c10/e5-11-06-01a.pdf $>$.

37 Anil, above $\mathrm{n} 35$.

38 Ibid.

39 Grandin, 'Making Slaughterhouses More Humane', above n 21.

40 CSIRO Meat Industry Services, 'Meat Technology Update', above n 33.

41 C B Johnson et al, 'Pain Perception at Slaughter' (2012) 21 Animal Welfare 113. 
Electrical stunning can also be applied to the body with consequent cardiac arrest, but this is not acceptable for halal practice. ${ }^{42}$ Other methods not in routine use include: standard firearms, water jets as used in industrial cutting of metals, and severing of the spinal cord at $\mathrm{C} 1 / 2^{43}$

\section{E Other Aspects of Killing}

Even without the issues raised by Brand in the primary article, transportation to slaughter is a stressful experience. For example, about 0.1 per cent of pigs die in transit and 0.05 per cent die in holding pens, with another $0.3-0.5$ per cent becoming stressed or fatigued prior to slaughter. ${ }^{44}$ Lambs killed in standard abattoirs had greater stress biochemistry and more vocalization than those killed in a transportable abattoir. ${ }^{45}$

Once the animals are in the abattoir, marshalling and moving can be distressing or painful. Electric prods are commonly used to move animals. These deliver a high voltage/low amperage shock, which is painful. Falls may also occur in the narrow confines of the ramps used, which may be directly painful and can cause distress from the difficulty of attempting to rise in a narrow confine with animals bearing down from behind.

A key component of killing is restraint. Restraint is often distressing and is judged by the frequency with which behavioural responses are seen. In an audit of 10 abattoirs in several developed countries using a variety of animal positioning, in non-stunned animals the best position had 35 per cent of animals struggling, and 10 per cent vocalizing. ${ }^{46}$

\section{F High Standard Performance and its Implications}

If we use the audit standards and numbers proposed by Grandin above as representing excellence in industrial practice, and combine them with the 2011 FAO statistics of all large animals killed in one year worldwide, ${ }^{47}$ we

42 Anil, above $\mathrm{n} 35$.

43 Ibid.

44 Madonna Benjamin, 'Pig Trucking \& Handling' (2005) 16 Advances in Pork Production 57.

45 Marit Skog Eriksen et al, 'Mobile Abattoir Versus Conventional Slaughterhouse-Impact on Stress Parameters and Meat Quality Characteristics in Norwegian Lambs' (2013) 149 Applied Animal Behavioral Science 21.

46 Velarde et al, above $\mathrm{n} 24$.

47 Grandin, 'Making Slaughterhouses More Humane': see above n 23 and accompanying text; Food and Agricultural Organization of the United Nations, see above $\mathrm{n} 2$ and accompanying text. 
can calculate some of the issues in the pre-killing phase of handling large animals for slaughter. These are outlined below in Table 1. 
Table 1 Pre-Killing Phase: number of animals worldwide (2011 figures)

\begin{tabular}{l|l|l} 
Process & Worldwide-excellent & Worldwide-adequa \\
\hline & & \\
Distress vocalization & 130000000 & -- \\
Fell & 26000000 & -- \\
Electrically prodded & 130000000 & 650000000
\end{tabular}

When we get to the slaughter itself, if we used penetrating captive bolt for killing all animals, our numbers would look like this:

Table 2 Worldwide Slaughter Phase: number of animals worldwide (2011 figures)

\begin{tabular}{l|l|l} 
Process & $\begin{array}{l}\text { Worldwide- } \\
\text { excellent }\end{array}$ & $\begin{array}{l}\text { Worldwide- } \\
\text { adequate }\end{array}$ \\
\hline $\begin{array}{l}\text { Captive bolt second } \\
\text { shot }\end{array}$ & 26000000 & 130000000
\end{tabular}

If we were to substitute electrical stunning for captive bolt killing, the numbers would be identical.

Thus even in 'excellent' practice, the necessity for 26 million animals to endure a second strike from the bolt-gun is far from a state of painless killing. If we are probably more realistic (Grandin feels 95 per cent is a standard that ought to be achieved $){ }^{48}$ that number is likely of the order of 100 million animals. This is not an issue of edge cases or small numbers.

\section{CONCLUSION}

For those who are concerned about the ethics of eating meat there is little reason to be satisfied with the status quo. To answer the critical questions posed, it is easy to conclude: first, that our best evidence is that direct incisional killing causes pain and may lead to significant suffering in some animals; secondly, that some forms of stunning may prevent this suffering; and thirdly, that correctly applied penetrating captive bolt killing does not cause pain. But this is to gloss over the deeper issue.

48 Grandin, 'Making Slaughterhouses More Humane', above n 21, 505. 
In actual practice, the technical difficulties in the use of non-incisional killing and stunning, guarantee that some animals will suffer pain. Furthermore, independent of the method of killing, all industrial methods require marshalling and restraint, with consequent distress in many animals. The bottom line is that, even with practices of 'best commercial ability', enormous numbers of animals experience pain or distress in the final period of their life regardless of how they are killed. Yes, there is a problem with the knife, but the real issue is not really about the knife. 